\title{
A participação do homem na saúde reprodutiva: o que pensam os profissionais de saúde*
}

PARTICIPATION OF MEN IN REPRODUCTIVE HEALTH: WHAT HEALTH PROFESSIONALS THINK

\author{
LA PARTICIPACIÓN DEL HOMBRE EN LA SALUD REPRODUCTIVA: \\ LO QUE PIENSAN LOS PROFESIONALES DE LA SALUD
}

Elizabeth Perez Galastro', Rosa Maria Godoy Serpa da Fonseca²

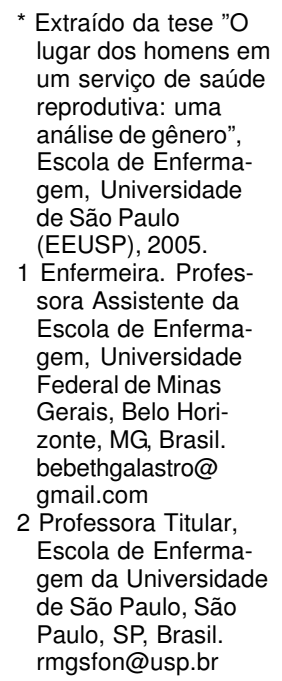

\begin{abstract}
RESUMO
Esta pesquisa teve como objetivo avaliar as concepções dos profissionais de saúde sobre a participação do homem nos diferentes aspectos do processo reprodutivo. Os dados foram coletados em um hospital filantrópico da periferia de Belo Horizonte-MG, mediante uma oficina de trabalho. Aqui é apresentado o tema $\mathrm{O}$ lugar dos homens no serviço de saúde reprodutiva, parte dos dados do estudo. Foi possível verificar que o homem acompanha sua mulher e o filho nos vários setores dos serviços, porém, mostra-se ausente nas situações de pósaborto e doação do filho. A precária infra-estrutura física e material do serviço tem sido um dos maiores obstáculos para a assistência integral
\end{abstract}

\section{DESCRITORES}

Medicina reprodutiva.

Saúde da mulher.

Identidade de gênero.

Homens.

\section{ABSTRACT}

This survey was aimed at analyzing health professionals' concepts concerning male participation in the different aspects of the reproductive process. The data were collected in a philan-thropic hospital in the outskirts of Belo Horizonte, in the State of Minas Gerais, by means of a workshop whose theme was: "Men's place in the reproductive health service". The data obtained are part of the results of this study. It was possible to observe that men go with their partners and children to many of the service's sectors, but are absent in situations like postabortion and child donation for adoption. One of the main obstacles for full assistance has been the precarious physical and material infrastructure of the services.

\section{KEY WORDS}

Reproductive medicine.

Women's health.

Gender identity.

Men.

\section{RESUMEN}

Esta pesquisa tuvo como objetivo analizar las concepciones de los profesionales de salud, sobre la participación del hombre en los distintos aspectos del proceso reproductivo. Los datos fueron recogidos en un hospital filantrópico de la periferia de Belo Horizonte, Minas Gerais, mediante un taller de trabajo. Aquí se presenta el tema "el lugar de los hombres en el servicio de la salud reproductiva", que es parte de los resultados del estudio. Fue posible verificar que el hombre acompaña a la mujer y al hijo en los varios sectores del trabajo de la salud, pero que él se muestra ausente en las situaciones del pos-aborto y de la donación del hijo. Uno de los mayores obstáculos para que consigamos una asis-tencia integral es la precaria infra-estructura física y material del servicio.

\section{DESCRIPTORES}

Medicina reproductiva.

Salud de la mujer.

Identidad de género.

Hombres. 


\section{INTRODUÇÃO}

Os serviços de saúde reprodutiva no Brasil, tradicionalmente se orientaram pela política centrada exclusivamente na mulher reprodutora. A partir dos anos oitenta essa política tomou uma nova direção com a criação do Programa de Atenção Integral à Saúde da Mulher (PAISM). As bases conceituais deste programa são referência e inspiração para a luta pela eqüidade de gênero na saúde e representa um avanço em relação à saúde da mulher ao propor um modelo baseado na assistência integral.

Com a Conferência Internacional sobre População e Desenvolvimento (CIPD) realizada no Cairo em 1994 e a IV Conferência Mundial sobre Mulheres realizada em Beijing, China em 1995, que ocorreram na década de noventa sob o patrocínio das Nações Unidas, uma ampla discussão ocorreu no sentido de ampliar os direitos sexuais e reprodutivos para que o homem e a mulher pudessem usufruir de uma vida sexual sadia, com acesso aos serviços de qualidade. Um novo aspecto foi introduzido nos documentos dessas Conferências que foi o da inclusão dos homens na questão da responsabilidade individual e social do comportamento sexual e reprodutivo. Isso ocorreu ao considerar que, se os homens mudassem seus padrões de comportamento sexual haveria uma transformação nos indicadores desfavoráveis de saúde da mulher.

A inclusão dos homens nas ações de saúde reprodutiva encontra-se implícita nos princípios do PAISM e claramente apresentados nos princípios e diretrizes do Sistema Único de Saúde (SUS) quanto a universalidade, eqüidade e integralidade das ações ${ }^{(1)}$.

Na área da concepção, hoje se discute muito sobre a necessidade de uma mudança nas práticas da assistência prestada a parturiente. O parto como evento fisiológico ou no caso em que haja risco à saúde dos envolvidos, é acompanhado de muita ansiedade e emoção. É seguramente um momento marcante na vida de uma mulher, e os profissionais de saúde devem proporcionar às parturientes experiências positivas.

No Brasil, assim como em boa parte do mundo, o modelo de assistência obstétrica é caracterizado por um alto grau de medicalização e abuso de práticas invasivas e desnecessárias. Esse processo de medicalização implicou em profundas mudanças nas diversas práticas de assistência á gravidez e ao parto, privando não só a mulher como seu companheiro e familiares de uma maior participação no evento. Assim, a Organização Mundial de Saúde, em 1996, elaborou recomendações que prestam assistência obstétrica, visando ao mínimo possível de intervenção que não esteja compatível com a segurança da mãe e da criança. Essas recomendações foram traduzidas pelo Ministério da Saúde no Brasil, em 2000. Para incentivar as instituições a iniciar um processo de humanização do parto e incorporação das recomendações da OMS, foi criado o Prêmio Galba de Araújo. Esse prêmio tem contribuído para a divulgação de algumas experiências criativas de mudanças institucional no Brasil, como as implementadas em um hospital filantrópico de Belo Horizonte, Minas Gerais, onde foi realizada esta pesquisa.

Desde a sua criação, esta instituição priorizou o atendimento humanizado à mulher e ao recém-nascido, incentivando o parto normal, o alojamento conjunto e o aleitamento materno, em uma constante busca pela otimização de um serviço humanizado e de qualidade. Na metade da década de noventa, iniciou-se uma nova cultura institucional, caracterizada pela redefinição do modelo gerencial, respaldado nos princípios do SUS e no modelo de Linha do Cuidado. Esta redefinição tem proporcionado a introdução de diversas práticas e estratégias na assistência prestada à mulher $\mathrm{e}$ ao recém-nascido, através da adesão das recomendações da OMS propostas, em 1985, na Conferência sobre Tecnologias Apropriadas para o Nascimento e Parto. No Brasil, o Ministério da Saúde também reconhece o direito da gestante de um acompanhante durante o trabalho de parto. O hospital vem acatando esta recomendação e implementando uma maior participação do companheiro junto à sua parceira enquanto ela estiver na instituição.

\section{OBJETIVO}

O objetivo desse trabalho foi analisar as concepções dos profissionais de saúde sobre a participação do homem nos diferentes aspectos do processo reprodutivo, visando proporcionar um espaço para que refletissem sobre questões relacionadas aos gêneros masculino e feminino e contribuir para a construção de estratégias que possibilitem a maior presença do homem nas diversas áreas de assistência.

\section{MÉTODO}

A escolha foi pela metodologia qualitativa que responde às questões do universo de significações referente aos valores, às crenças, aos estereótipos, atitudes e fenômenos que não podem se quantificáveis. Portanto, é uma abordagem que

incorpora a questão do significado e da intencionalidade como inerentes aos atos, às relações e às estruturas sociais, sendo essas últimas tomadas tanto no seu advento, quanto na sua transformação como construções humanas significativas ${ }^{(2)}$.

O referencial teórico adotado foi a Teoria das Representações Sociais e Gênero. Selecionou-se para apresentação neste artigo apenas os resultados referentes ao lugar dos homens na percepção dos profissionais de saúde. 
A técnica para a coleta de dados foi a oficina de trabalho por apresentar uma relação horizontal do pesquisador e pesquisado, pois fornece um espaço de discussão e tem como objetivo

resgatar os conhecimentos existentes, manifestar os sentimentos relativos à vivência, facilitar a expressão e a comunicação intergrupal, aliados à motivação para a discussão dos conteúdos ${ }^{(3)}$.

Participaram da oficina um total de sete profissionais: um médico, uma enfermeira, uma assistente social, duas psicólogas, uma auxiliar de enfermagem e uma ouvidora ${ }^{(a)}$, todos com vivências profissionais na área da assistência à saúde reprodutiva entre dois a dezoito anos. A oficina foi estruturada em dois encontros, que tiveram como temas: a construção da identidade masculina e feminina e o lugar dos homens no serviço de saúde reprodutiva.

Os encontros foram gravados e transcritos na íntegra. Os dados foram submetidos a analise do discurso que permite explorar as articulações que existem entre o indivíduo e a sociedade, tornando possível o

estudo da afetividade, do engajamento, do identitário e de suas relações com as formas, as lógicas e o funcionamento do pensamento social(4).

Ao final da análise, foram obtidas duas categorias centrais que correspondem aos temas das sessões da oficina com suas respectivas sub-categorias A construção das identidades masculinas e femininas e $O$ lugar dos homens no serviço de saúde reprodutiva. Neste texto será apresentado exclusivamente a análise e discussão da categoria o lugar dos homens no serviço de saúde reprodutiva. Os dados desta categoria foram obtidos durante a segunda sessão da oficina de trabalho, em que se utilizou uma dinâmica facilitadora denominada Catavento. O catavento é um brinquedo que imita a técnica do moinho de vento e é posto em movimento pela força de algo invisível como o vento. A proposta desta técnica é exatamente imitar os movimentos de um catavento, só que movido pelas idéias, opiniões e reflexão dos componentes do grupo. Cada participante recebe uma folha com o desenho de um catavento com três hastes e, em cada uma delas, uma questão para reflexão: o lugar dos homens no serviço, o que penso e o que faço. Esta técnica proporciona um ir e voltar das discussões, uma vez que, a proposta é que após cada discurso, nova onda de reflexões aconteça.

O projeto foi apreciado por um Comitê de Ética e os profissionais foram esclarecidos acerca do objetivo, finalidade do estudo, forma de coleta de dados e de apresentação do relatório, garantindo o anonimato das informações. No dia

(a) Ouvidora: nome designado pela instituição aos voluntários representantes dos usuários no serviço. da realização da oficina foi entregue uma carta esclarecendo sobre a pesquisa e o termo de consentimento livre e esclarecido para a concordância final. Foi dada a liberdade de deixar o estudo em qualquer momento.

\section{APRESENTAÇÃO DOS RESULTADOS}

Dentre os serviços, desta instituição, a contracepção é o setor no qual os profissionais têm uma longa experiência no oferecimento de quase todos os métodos conhecidos e disponíveis, além de incentivado a maior participação do companheiro na escolha do método contraceptivo. Isto porque, desde o início, tem trabalhado em parceria com organizações não-governamentais, para o oferecimento dos métodos contraceptivos à comunidade e no treinamento dos profissionais. Na área da concepção, o hospital nunca negou ao companheiro da mulher a sua presença, mas não era uma prática generalizada e rotineira, dependendo muito do profissional que atendia. Entretanto, como aparece em um dos discursos, hoje ele já é um usuário, pode-se ver o homem transitando em todos os setores do hospital.

\section{Não tem lugar aqui onde nós falamos assim, homem não pode entrar, mas antigamente não era assim, hoje ele já é um usuário. Pelo menos nós não proibimos de entrar em momento nenhum.}

É uma prática que foi resgatada e apoiada principalmente pelas recomendações da OMS e que tem, de certa forma apresentado resultados satisfatório. A maternidade é responsabilidade do casal e essas recomendações devem ser aproveitadas para introduzir o homem no acompanhamento da mulher em todo o processo reprodutivo. Os debates de gênero que vem ocorrendo nas últimas três décadas, têm contribuído e repercutido nos modelos de assistência à saúde. Os serviços podem beneficia-se do enfoque de gênero em todas as esferas da saúde reprodutiva e proporcionar a interação profissional/cliente-homem nas áreas, principalmente, no planejamento familiar, parto, pós-parto, pós-aborto e prevenção de violência ${ }^{(5)}$. De acordo com os discursos dos profissionais, o hospital tem procurado introduzir o homem no serviço como revela o seguinte discurso.

\section{Na maternidade, cortando o cordão umbilical, festejando o nascimento, no planejamento familiar fazendo a vasectomia, no pré-natal acompanhando a usuária e na neonatologia, o pai vivenciando junto com a mulher o neném internado.}

Durante a oficina, os profissionais não hesitaram em afirmar que o homem estava presente em todos os lugares, porém, ao serem questionados sobre a presença dele no pósaborto, um silêncio inicial interrompeu as discussões. $\mathrm{O}$ significado do silêncio é a própria produção de sentidos,

não é o vazio, o sem sentido, ao contrário, ele é o indício de uma totalidade significativa. Isto nos leva à compreensão do vazio da linguagem como um horizonte e não como falta ${ }^{(6)}$. 
O tema aborto é complexo e repleto de contradições e dúvidas, causando, na maioria das vezes, incômodo e necessidade de reflexão prévia ao se falar do assunto. Dessa forma, o início da discussão foi o silêncio e, logo em seguida, vieram os discursos.

As mulheres que têm abortamento nós vemos menos homens com elas, é mais raro. A participação é menos, isto eu não tenho dúvidas, você pode chegar lá agora e ver uma mulher que está se submetendo a uma curetagem, são poucas as mulheres que têm o acompanhante.

Espaço ele tem, é a mesma coisa. O espaço ele existe, só que não é ocupado. No pós-aborto a presença do homem é bem menor do que no parto.

A experiência de um aborto, se espontâneo ou provocado, é freqüentemente acompanhada de muita ansiedade, incerteza e sofrimento. Os serviços de um modo geral estão pouco atentos a isto. Além disto, os homens nem sempre estão presentes ou por omissão, ou por achar que esta experiência, assim como o parto, é coisa de mulher. Os estudos sobre aborto, na maioria, se referem à população feminina. No que concerne a reprodução biológica, as mulheres são fecundadas por homens. No entanto, são raros os estudos acerca do papel masculino neste evento, principalmente nos países em desenvolvimento em que o aborto é considerado como prática ilegal ${ }^{(7-8)}$. Em um estudo conduzido pelo Population Concil ${ }^{(5)} \mathrm{em}$ cinco hospitais no Kenia, concluiu que uma em cada três internações ocorridas em enfermarias ginecológicas era de aborto induzido. Neste estudo, somente $14 \%$ dos homens entrevistados tinham recebido alguma informação das condições de sua parceira, enquanto que 94\% disseram que eles gostariam de ter recebido tais informações. Similarmente, $15 \%$ dos homens receberam informações sobre planejamento familiar depois do procedimento, $\mathrm{e}$ 92\% disseram que eles gostariam de ter recebido informações sobre planejamento familiar.

A instabilidade da relação da mulher com seu parceiro ou falta de apoio emocional e econômico por parte do companheiro ao tomar conhecimento da gravidez, têm sido mencionado pelas mulheres como um dos principais motivos para a prática do aborto ${ }^{(9)}$. Não há como desconsiderar as diferenças de gênero, no que se refere ao significado que o aborto tem para as mulheres e para os homens, mesmo que homens e mulheres assumam sua participação no processo reprodutivo, no imaginário de cada um, as conotações são distintas. Para o homem, o aborto, pode representar maior responsabilidade ao ter que assumir um filho. Para a mulher pode significar a autonomia do próprio corpo e evitar as possíveis dificuldades inerentes à gravidez, impossibilitando concretizar projetos de vida ${ }^{(10)}$. O aborto é um setor da assistência na área da saúde reprodutiva que envolve valores e princípios morais e religiosos, necessitando de um maior investimento e adoção de práticas inovadoras em que os profissionais possam desenvolver uma abordagem diferen- ciada a clientela, valorizando a subjetividade das diferenças de gênero e das necessidades individuais. Para os profissionais deste estudo, na maioria das vezes as mulheres estão sozinhas neste momento, independente de ser aborto provocado ou não, assim como também estão desacompanhadas quando querem doar o filho.

É fato que o vínculo mãe e filho faz-se mais precocemente do que com o pai. Ao gerar um filho em seu corpo, a mulher inicia uma relação mais intensa e próxima com a criança. Quando se fala em aborto e doação de um filho, o que se pensa é que provavelmente não houve uma responsabilização pela conduta contraceptiva de ambas as partes. Compreender o sentido da responsabilidade é tarefa para outras investigações, mas, de qualquer forma, homens e mulheres, responsáveis ou não, devem ser tratados pelo serviço de forma acolhedora, no sentido de aproveitar o momento e proporcionar aos usuários escolhas contraceptivas autônomas e responsáveis.

A recomendação do Ministério da Saúde sobre o direito da mulher a um acompanhante não implica que seja necessariamente um parceiro, podendo ser um familiar ou uma pessoa de confiança da mulher. Porém, esta instituição tem dado prioridade e incentivado a participação do companheiro, desde o pré-natal. O pai tem sido considerado fundamental no ideário do casal grávido. A inserção do companheiro nesse evento, é um direito reprodutivo, além de ser um dos momentos importantes para o estabelecimento de vínculos precoces entre pai e criança sendo considerado como forma preventiva de violência doméstica à criança, ao abandono da família e à deliquiência juvenil ${ }^{(11)}$. Além disso, é o momento oportuno para despertar a emergência do pai cuidador.

Esse ideário de pai cuidador e pai grávido teve início nos anos setenta nos Estados Unidos e Europa, fruto das reivindicações feministas e de profissionais de saúde adeptos desse ideário ${ }^{(12)}$.

O hospital por sua vez, tem criado situações para que o casal possa vivenciar experiências agradáveis e, ao mesmo tempo, proporcionar aos profissionais momentos de gratificação e prazer no processo de trabalho.

\begin{abstract}
Ele tem participado demais, porque a mulher está lá na sala, estão cuidando dela para levar para o alojamento conjunto, enquanto isto o pai está lá acompanhando os primeiros cuidados do filho.
\end{abstract}

Eu penso que é importante nós permitirmos aos homens vivenciarem essas emoções.

O serviço ao proporcionar esta experiência, está possibilitando ao homem a obtenção de uma compreensão mais profunda de si mesmo, especialmente no nível das emoções, contribuindo para as transformações das relações pessoais, da sexualidade e da vida doméstica. 
O papel de gênero aglutina as expectativas dos modelos de comportamento social apropriado de cada um dos sexos. Toda cultura tem estabelecido o que se espera da mulher e do homem de uma forma rígida ao longo dos tempos, chegando aos estereótipos. Assim, os estereótipos de maternidade e paternidade na nossa sociedade estão profundamente cristalizados passando a ser considerados como naturais. O modelo de paternidade tradicional é o homem que provê, sustenta, protege e não demonstra emoções. O modelo de maternidade tradicional é o da mulher que cuida e a maternidade é sua marca identitária.

Assim, podemos dizer que a mulher ao maternar está colocando em prática tudo aquilo que aprendeu quando era criança e brincava de boneca. Essa atitude está relacionada às gratificações afetivas socialmente aprendidas ao cuidar do seu filho. Por outro lado, o homem aprendeu quando criança a brincar com o instrumental, com o mecânico e a lidar com o racional. As gratificações para muitos podem parecer atitudes estranhas, uma vez que nunca foram aprendidas. A experiência da paternidade pode ser o início dessa aprendizagem. De acordo com os profissionais, os homens têm participado de uma maneira muito tranquila e sem medo de críticas, porque todos estão fazendo a mesma coisa, num ambiente que eles podem demonstrar os sentimentos e as emoções sem serem criticados e ridicularizados, muito pelo contrário, eles são o tempo todo estimulados e motivados para isso.

Com as transformações sociais, cultuais e econômicas do mundo atual, o homem vem sendo solicitado a participar mais efetivamente do cotidiano familiar, principalmente no que se refere aos cuidados com os filhos, um novo modelo de pai tem surgido. Esse modelo tem recebido diversas denominações como o novo pai, paternagem, pai-mãe e outros. O certo é que um novo modelo de paternidade vem sendo construído. Não se trata apenas de mera troca de lugar, mas a construção de um outro lugar e de outros sentidos ${ }^{(13)}$.

Os profissionais, ao incorporarem o homem no serviço, têm rompido com valores, crenças e atitudes cristalizadas ao longo da sua formação profissional e social, adotando formas diferente de pensar e consequentemente agindo de uma nova maneira.

No entanto, o que mais incomoda aos profissionais no seu cotidiano de trabalho é a falta de infra-estrutura no que se refere a carência de recursos físicos e materiais. Estas questões conseqüentemente interferem no desempenho e na qualidade da atenção. A qualidade de atenção seria a prestação de assistência capaz de alcançar melhor equilíbrio entre os benefícios de saúde e os riscos. Portanto, o custo monetário, a expectativa e valores dos usuários, são fatores considerados facilitadores ou obstáculos para alcançar um bom padrão de qualidade ${ }^{(14)}$

Diante das dificuldades estruturais básicas que os profissionais enfrentam no dia a dia, eles têm buscado alternativas criativas, possíveis para amenizar as situações que possam dificultar a incorporação do homem no processo reprodutivo. Desta forma, o hospital ao propor uma reestruturação do seu modelo de gestão pautado na linha do cuidado, está passando por mudanças significativas em duas esferas. A primeira refere-se à organização do serviço no sentido de otimização produtiva referente a gastos, financiamento, produtividade, ociosidade etc. A segunda esfera diz respeito aos cuidados propriamente ditos. A linha do cuidado não está pautada apenas pelo plano terapêutico, mas, também, visa atender aos anseios e necessidades psico-social do usuário. Tradicionalmente, a clientela, usuária do hospital, sempre foi constituída pela mulher e pela criança. Hoje, está acrescida de um terceiro usuário que é o homem, cuja presença tornou-se constante no serviço e em quase todos os setores. Para isto, esta instituição vem buscando novas formas de trabalho, investindo no aprimoramento das tecnologias duras, leve-duras e leves ${ }^{(15)}$.

Quanto à tecnologia dura, o hospital dispõe de poucos recursos para sanar todas as demandas materiais de que precisa. Isso, em parte se deve por ser esta instituição, quase que exclusivamente, dependentes dos honorários do SUS (96\%), consequentemente a sua infra- estrutura não é suficiente, nem adequada para enfrentar as novas mudanças, gerando críticas e resistência por parte dos profissionais e dos usuários.

A questão do espaço, muitas vezes as usuárias querem ter os acompanhantes, querem os homens ao lado delas, mas o que acontece, quando está todo mundo junto, às vezes sai críticas por causa disso.

As tecnologias leveduras estão relacionadas com o conhecimento e o saber dos profissionais na prestação do cuidado. O cuidado em saúde é, por natureza, multidisciplinar, dependendo da conjugação do trabalho de vários profissionais. Assim, a integralidade da atenção será medida pelo grau de articulação entre os profissionais na execução das práticas ${ }^{(16)}$. Tradicionalmente, as instituições de saúde funcionam numa forma de coordenação, ou seja, múltiplas coordenações apoiadas na lógica de cada profissão. Isso, conse-quentemente dificulta a comunicação entre as diversas profissões. Conforme o relato a seguir esta comunicação parece estar começando a acontecer no cotidiano de trabalho.

\section{A própria equipe reconheceu que foi importante, esse aco- Ihimento da psicologia, para mim isto foi muito bom neste sentido, no espaço.}

A tecnologia leve, é o espaço das relações e interações entre os indivíduos, possibilitando o encontro e a comunicação articulada de forma mais leve e solidária. Nos discursos dos profissionais, pode-se perceber que os mesmos já estão incorporando em suas ações uma nova postura, ou seja, de relação com o outro/usuário, que é um sujeito provido de singularidade, de desejo, de saber e história. 
O acolhimento que eu quero mostrar não é só abrir as portas. É responsabilizador, este é o verdadeiro acolhimento, porque as pessoas acham que tem que ter acompanhante e abre as portas.O acolhimento é um acolhimento vinculado.

Ter vínculo é você responsabilizar por ela, não deixar solta.

Fornecer uma assistência integral requer dos profissionais um exercício de reflexão constante do fazer e do pensar. Os conceitos referidos por eles são conceitos recentes pois fazem parte do novo modelo de assistência que o hospital quer adotar, ou seja,centrado no usuário.

\section{CONCLUSÃO}

Na percepção dos profissionais de saúde, os homens, já transitam em todos os setores da instituição onde o estudo foi realizado, compartilhando com a companheira os vários momentos vivênciados no período da internação. Porém, os profissionais revelam um vazio da figura masculina em dois momentos cruciais, o pós-aborto e a doação do filho. Fato que, por si só, demonstra a necessidade de um aprofundamento maior desta realidade em estudos posteriores.

\section{REFERÊNCIAS}

1. Galvão L. Saúde sexual e reprodutiva, saúde da mulher e saúde materna: a evolução dos conceitos no mundo e no Brasil. In: Galvão L, Díaz J, organizadores. Saúde sexual e reprodutiva. São Paulo: Hucitec; 1999. p. 165-79.

2. Minayo MCS. O desfio do conhecimento: pesquisa qualitativa em saúde. $8^{\text {a }}$ ed. São Paulo: Hucitec; 2004.

3. Chiesa AM. Mulher, corpo e agravo à saúde: do ingênuo ao crítico através do conhecimento.In: Fonseca AMGS, organizadora. Mulher e cidadania na nova ordem social. São Paulo: Núcleo de Estudos da Mulher e Relações Sociais de Gênero NEMGE/USP; 1996.

4. Anadon M, Machado PB. Reflexões teórico-metodológicas sobre as representações sociais. Salvador: Uneb; 2001.

5. Ringheim $\mathrm{K}$. When the client is male: client provider interation from a gender perspective. Int Fam Plann Perspect. 2002; 28(3): 170-5.

6. Orlandi EP. As formas do silêncio: no movimento dos sentidos. $4^{\mathrm{a}}$ ed. Campinas: UNICAMP; 1997.

7. Johansson A, Nga NT, Huy TQ, Dat DD, Holmgren K. Husbands' involvment in abortion in Vietnam. Stud Fam Plann. 1998;29(4):401-13.

8. Duarte GA, Alvarenga AT, Osis MJMS, Faúndes A, Hardy E. Pespectivas masculinas acerca do aborto provocado. Rev Saúde Pública [periódico na Internet].2002[citado 2004 out. 14];36(3):[cerca de 7 p.]. Disponível em: http://www.scielo.br/ pdf/rsp/v36n3/10487.pdf

9. Costa SH. Aborto provocado: a dimensão do problema e a transformação da prática. In: Giffin K, Costa SH, organizadoras. Questões da saúde reprodutiva. Rio de Janeiro: FIOCRUZ; 1999. p. 163-84.
Os profissionais, ao refletirem sobre o lugar dos homens na instituição, desvelaram o processo de transformação que o hospital vem enfrentando nos últimos anos no sentido de incorporar o homem ao serviço. Essa nova realidade, tradu-zida pela visibilidade do usuário masculino no serviço que, aparentemente, parecia impossível, está se tornando realidade. Os novos valores, ao serem aceitos pelo grupo estudado, abrem caminhos para o processo de construção de um novo paradigma.

Esta instituição ao propor uma maior participação do homem no serviço de saúde reprodutiva, está incorporando um dos princípios doutrinários do SUS que é o da integralidade das ações. Este princípio concebido como uma ação que percebe o ser humano como sujeito inteiro requer dos profissionais uma ampliação e compreensão do processo saúde-doença que ultrapasse o modelo biológico. Isto significa romper com velhos paradigmas e adotar um novo. Desta forma, percebe-se nos relatos dos profissionais a incorporação dos novos conceitos pertencentes à linha do cuidado centrada no usuário, ou seja, a forma como ele é acolhido, o vínculo e responsabilização criada entre profissionais e clientes. Proposta esta, que visa à integralidade do cuidado e à qualidade da assistência.

10. Arilha M. Homens, saúde reprodutiva e gênero: o desafio da inclusão. In: Giffin K, Costa SH, organizadoras. Questões da saúde reprodutiva. Rio de Janeiro: FIOCRUZ; 1999. p. 455-67.

11. Carvalho MLM. Participação dos pais no nascimento em maternidades públicas: dificuldades institucionais e motivações dos casais. Cad Saúde Pública [periódico na Internet]. 2003 [citado 2004 jul. 27];19 Supl 2. Disponível em: http:// www.scielo.br/pdf/csp/v19s2/a20v19s2.pdf

12. Hotimsky SN, Alvarenga AT. A definição do acompanhante no parto: uma questão ideológica? Rev Estud Feminista [periódico na Internet]. 2002[citado 2004 ago. 10];10(2): [cerca de 21 p.]. Disponível em: http://www.scielo.br/pdf/ref/v10n2/ 14971.pdf

13. Medrado B. Homens na arena do cuidado infantil: imagens veiculadas pela mídia. In: Arilha M, Unbehaum SG, Medrado $\mathrm{B}$, organizadores. Homens e masculinidades: outras palavras. $2^{a}$ ed. São Paulo: Edições 34; 1998. p. 145-61.

14. Pinheiro R, Guizard FL. Cuidado e Integralidade: por uma genealogia de saberes e práticas no cotidiano. In: Pinheiro R, Mattos RA. Cuidado: as fronteiras da integralidade. São Paulo: Hucitec; 2004. p. 21-36.

15.Mehy EE. Saúde: cartografia do trabalho vivo. São Paulo: Hucitec; 2002.

16. Cecílio LCO, Mehy EE. A integralidade do cuidado como eixo da gestão hospitalar. In: Pinheiro R, Mattos RA, organizadores. Construção da integralidade: cotidiano, saberes e práticas em saúde. Rio de Janeiro: UERJ/IMS/ABRASCO; 2003. 